\title{
Cyclodestructive Procedures
}

\author{
Sima Sayyahmelli and Rakhshandeh Alipanahi \\ From the Glaucoma Division, Tabriz Medical Sciences University, Tabriz, \\ Iran
}

\section{Introduction}

Several method used when an initial filtering procedure is not adequate to control the refractory glaucoma and when resumption of medical therapy,revision of original surgery, repeat filtering surgery at a new site, or aqueous shunt implantation is not successful; finally all cyclodestructive procedures reduce aqueous secretion by destroying part of the secretory ciliary epithelium portion of the ciliary body including cyclocryotherapy, contact and noncontact trans-scleral thermal lasers such as continuous-wave with the 1064-nm Nd:YAG, argon, and portable $810-\mathrm{nm}$ semiconductor Diode laser.1-4 Cryotherapy, the original technique, is increasingly being supplanted by laser photocoagulation, originally with the 1064-nm Nd:YAG laser and lately with the portable 810-nm semiconductor Diode laser.2-3 An endoscopic laser delivery system has been advocated for use with cataract surgery or in pediatric, pseudophakic, or aphakic eyes. Use of the argon laser aimed at the ciliary processes through a goniolens is possible in a small percentage of patients. Transcleral diod laser cyclophotocoagulation (CPC ) reducing aqueous secretion by destroying, is generally considered to be better tolerated and perhaps more effective than cyclocryotherapy, and it has a lower incidence of complications such as postoperative pain, inflammation, phthisis bulbi and retinal detachment, possibly because of better absorption of this wave length by the pigmented tissues of the ciliary body. Diode laser cyclophotocoagulation (CPC) is often the choice treatment of lOP-lowering in painful blind eyes or in eyes unlikely to respond to other modes of therapy. Interventions methods such as retrobulbar alcohol injection, retrobulbar chlorpromazine injection, or enucleation are rarely performed now because of improved CPC techniques. Treatment of glaucoma in the pediatric population is frequently challenging and may require multiple surgical interventions. In the past it was used mainly in uncontrolled end-stage secondary glaucoma with minimal visual potential mainly to control pain. However it is now apparent that it can also be used in eyes with reasonably good vision which may be retained provided control of IOP is adequate. This section studies the indications, success rate and long term efficacy and complications of the cyclodestructive procedures in refractory glaucoma. Laser cycloablation is generally considered to be better tolerated and perhaps more effective than cyclocryotherapy.3,4 The most commonly used technique for cyclodestructive surgery is the transscleral approach, in which the destructive element must pass through conjunctiva, sclera, and ciliary musculature, before reaching and destroying the ciliary processes. These procedures have the advantages of being noninvasive and relatively quick and easy because of variable success in adults (34-92\%) and significant postoperative pain and complications including phthisis and retinal detachment, transscleral neodymium:YAG (Nd:YAG) and Diode lasers are replacing 
cyclocryotherapy as the preferred form of cyclodestruction in these eyes.5-7 The cyclophotocoagulation has a lower incidence of complications such as pain, postoperative inflammation and phthisis bulbi, possibly because of better absorption of this wave length by the pigmented tissues of the ciliary body.7-9 Several methods of Diode laser photocyclocoagulation have been reported to lower IOP and reduce pain in the eyes of refractory glaucoma Diode cyclophotocoagulation and sequential tube shunt following primary tube shunt failure in childhood glaucoma showed similar efficacy and complication rates. Ten to fifty percent of patients with primary congenital glaucoma fail goniotomy surgery and require further surgical intervention, Childhood glaucoma associated with systemic or ocular anomalies and secondary glaucoma such as that associated with congenital aphakia or pseudophakia have a worse surgical prognosis compared to primary congenital glaucoma. Trabeculectomy surgery with adjunctive mitomycin has a lower chance of successful control of children less than two years of age and in children who have had congenital cataract surgery. Additionally, compared to adults, the adjunctive use of anti-fibrotic agents with trabeculectomy in children may be associated with greater risk of late bleb-related infections. When a tube shunt fails to adequately control the intraocular pressure, limited treatment options remain. These options include a sequential tube shunt in another quadrant of the eye revision or replacement of the existing tube shunt, or a cyclodestructive procedure (usually transscleral or endoscopic Diode cyclophotocoagulation or cyclocryotherapy). Both tube shunts and transscleral Diode cyclophotocoagulation have been examined for treatment of refractory pediatric glaucoma. Compare the results of Contact Diod Laser Cyclophotocoagulation Versus Cyclocryotherapy in Refractory Glaucoma. ${ }^{10-15}$

Ciliary ablation is indicated to lower $\mathrm{lOP}$ in eyes that have glaucoma resistant to conventional medical and surgical therapies (refractory glaucoma, neovascular glaucoma, congenital glaucoma, secondary glaucoma, Post-surgical glaucoma, poor visual potential or that are poor candidates for incisional surgery(because of the small risk of sympathetic ophthalmia), painful blind eyes or in eyes unlikely to respond to other modes of therapy were treated with transscleral Diode laser Cyclophotocoagulation (CPC).

Ciliary ablation is relatively contraindicated in eyes with good vision because of the risk of loss of visual acuity.

Preoperative evaluation is the same as for incisional glaucoma surgery.

\section{Methods and considerations}

All patients signed an informed consent for the Ciliary body ablation procedures, after an explanation of the risks and benefits. Cyclophotocoagulation was performed under local anaesthesia (A sub-Tenon or peri bulbar ) with the Laser settings arc 1.5-2 sec and 1500$2000 \mathrm{~mW}$ with semiconductor Diode laser system (810 nm laser wavelength) with a spherical polished tip oriented by a handpiece, "G-Probe.". Figures 1 and 2. Duration was set at $2000 \mathrm{~ms}$ ( 2 seconds), and the initial power setting was $1750 \mathrm{MW}$. After the edge of the probe is aligned with the limbus, approximately $17-19$ applications are placed $270^{\circ}$ around the limbus, with a power of 1.5-2 Wand a duration of approximately 2 seconds The power was increased in $250 \mathrm{MW}$ increments to a maximum of $2000 \mathrm{MW}$ until an audible 'popping' sound is heard, and then the power was reduced by $250 \mathrm{MW}$ to just below that level. Approximately 2-40 burns arc (typically five per quadrant for 270 degrees of treatment) placed $1.2 \mathrm{~mm}$ posteriorly to the limbus over $180^{\circ}$ but avoiding the posterior ciliary nerves 
at 3 and 9 o'clock. In all cases, the probe tips were carefully examined. The Diode laser handpiece attachment from one manufacturer is shown in figure 2. A strong topical steroid is prescribed hourly on the day of treatment and then q.i.d. for 2 weeks. Oral non-steroidal anti-inIlammatory agents are prescribed for 2 days. Figure 1 showed cyclodestructive procedures to relieve pain. Figure 2 showed Semiconductor Diode laser. Figure 3 showed "G probe" handpiece for contact Diode TCP.

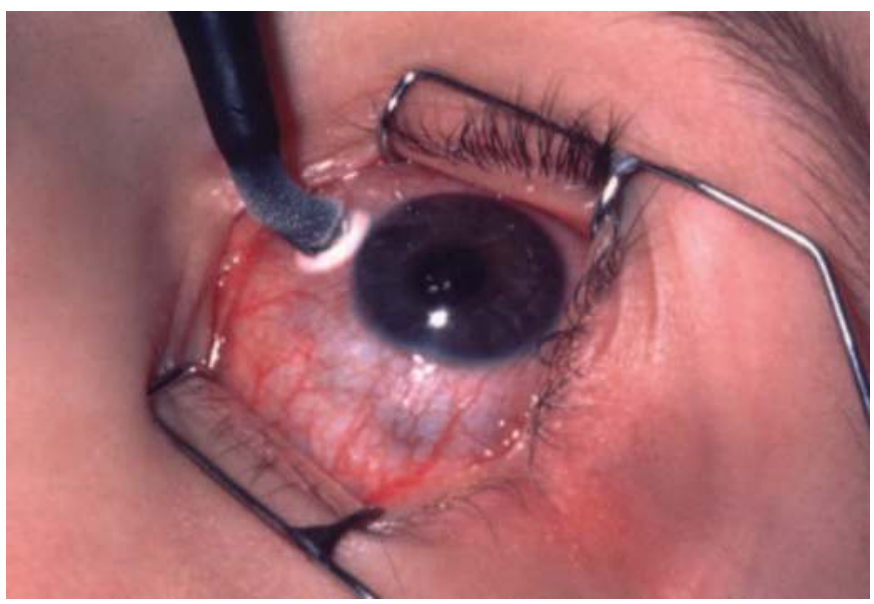

Fig. 1. Cyclodestructive procedures to relieve pain

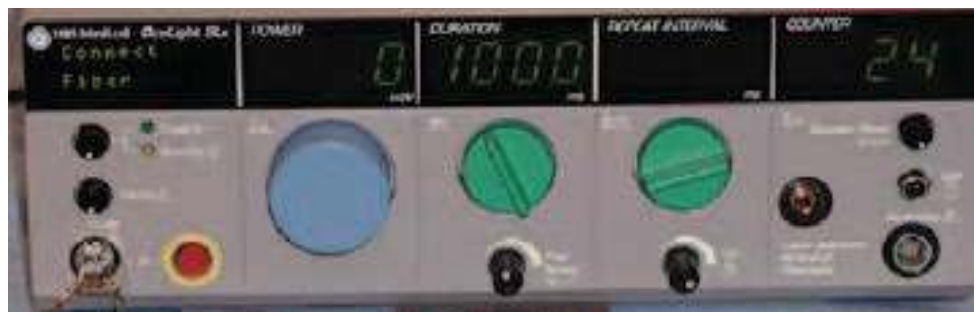

Fig. 2. Semiconductor Diode laser (IRIS Oculight SLx, Iris Medical Inc) for Diode contact TCP

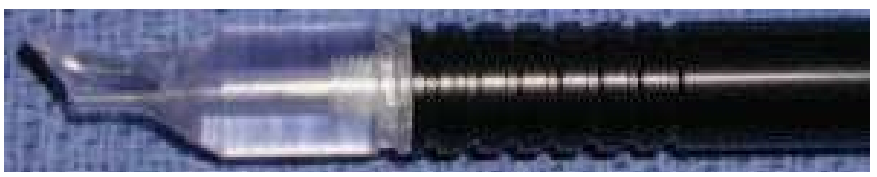

Fig. 3. Showed "G probe" handpiece for contact Diode TCP

Frequently more than one treatment session is required for adequate pressure control. The outcome of cycloDiode therapy was determined in terms of:

1. Success rate: defined as the percentage of eyes achieving and IOP between 5 and $21 \mathrm{~mm}$ $\mathrm{Hg}$ with or without topical medication with cessation of oral carbonic anhydrase inhibitor use in all eyes after cycloDiode therapy at their final follow-up visit. 
2. Response rate: defined as the percentage of patients achieving $>30 \%$ drop from baseline IOP with cessation of oral carbonic anhydrase inhibitor use. This included eyes that developed hypotony (IOP<5mm $\mathrm{Hg}$ ).

3. Failure rate: defined as percentage of patients who developed hypotony (IOP $<5 \mathrm{~mm} \mathrm{Hg}$ ) or phthisis, or those whose IOP drop was $<30 \%$ from baseline.

The success rate is dependent on the type of glaucoma, frequently more than one treatment session is required for adequate pressure control and the procedure has to be repeated. Pain relief is generally good. After surgery intra ocular pressure and mean number of antiglaucoma medications would be dropped.

Criteria for success included intraocular pressure (IOP) of $21 \mathrm{mmHg}$ or less with no devastating complications or need for further glaucoma surgery.

Pain following these procedures may be substantial, and patients should be provided with adequate analgesics, including narcotics, during the immediate postoperative period.

Cyclophotocoagulation may be associated with vision loss, prolonged hypotony, pain, inflammation, cystoid macular edema, hemorrhage, and even phthisis bulbi. Sympathetic ophthalmia is a rare but serious complication. Mildpostoperative pain and anterior segment innammation are common. Serious complications are rare and include conjunctival burns, prolonged uveitis, hyphema, chronic hypotony, phthisis bulbi, scleral thinning, corneal decompensation and retinal or choroidal detachment. However, since the aim of the procedure is usually to relieve pain. Vision-threatening complications do not have the same significance as those following conventional filtering procedures.

Transscleral Diode laser cycloablation is a recognized therapeutic approach to refractory glaucoma that involves photocoagulation of the pars plicata of the ciliary body with consequent reduction of aqueous secretion.7,11 Diode laser cyclophotocoagulation appeared to be an effective and safe primary surgical treatment of medically uncontrolled chronic angle closure glaucoma, with intraocular pressure lowering effect persisting for up to two years. ${ }^{16}$

TSCPC has a significant ocular hypotensive effect on glaucoma refractory to both tube shunt and medical therapy. ${ }^{17}$

An unqualified success after cycloablation would be the attainment of a target IOP without the need for further medication, coupled with preservation of visual function. CycloDiode therapy appears to be effective in lowering IOP, in both the short and long term. Endoscopic cyclophotocoagulation (ECP) was introduced as an alternative to trans-scleral cyclophotocoagulation for treating refractory glaucomas in order to minimise complications such as phthisis and hypotony by providing direct visualisation of the ciliary processes. Glaucoma following penetrating keratoplasty, which has an incidence ranging from $10-52 \%$, often proves refractory to medical treatment.1-3 We introduce a case of refractory post-PKP glaucoma in order to demonstrate the efficacy of ECP in treating post-PKP glaucoma and to describe its potential delayed effect in achieving intraocular pressure control Diode Laser Transscleral Cyclophotocoagulation as Primary Surgical Treatment for Medically Uncontrolled Chronic Angle Closure Glaucoma Long-Term Clinical Outcomes.17 Endoscopic cyclophotocoagulation (ECP) was introduced as an alternative to trans-scleral cyclophotocoagulation for treating refractory glaucomas in order to minimise complications such as phthisis and hypotony by providing direct visualisation of the ciliary processes. Glaucoma following penetrating keratoplasty, which has an incidence ranging from $10-52 \%$, often proves refractory to medical treatment. ${ }^{1-3}$ We introduce a case of refractory post-PKP glaucoma in order to demonstrate the efficacy of ECP in treating post-PKP glaucoma and to 
describe its potential delayed effect in achieving intraocular pressure control Diode Laser Transscleral Cyclophotocoagulation as Primary Surgical Treatment for Medically Uncontrolled Chronic Angle Closure Glaucoma Long-Term Clinical Outcomes Diode Laser Transscleral Cyclophotocoagulation for Refractory Glaucoma. ${ }^{18}$

Contact Diode laser transscleral cyclophotocoagulation is useful in eyes with refractory glaucoma in which the risks of outflow surgery are deemed unacceptable, Diode laser transscleral cyclophotocoagulation (DCPC) is one of the most widely used methods of ciliary body ablation, with reported success rates ranging from $40 \%$ to $80 \%$ cyclodestructive procedures are generally reserved for eyes with glaucoma refractory to other forms of medical or surgical intervention. In the past 10 years, cyclocryotherapy has been replaced by other techniques, especially laser cyclophotocoagulation with Nd:YAG or Diode laser systems, $^{5-10}$ that achieve good results with a lower complication rate. ${ }^{19-24}$ Diode laser transscleral cyclophotocoagulation is effective in lowering the intraocular pressure in chronic angle-closure glaucoma and its effect lasts for at least 1 year. ${ }^{20}$ Transscleral Diode laser cyclophotocoagulation is an effective and safe method for the treatment of advanced, refractory glaucoma. However, repeated treatments are often necessary. Success of treatment depends on the age of patients, previous surgery, and the type of glaucoma. ${ }^{21}$ Types of glaucoma that are often difficult to treat include neovascular glaucoma, posttraumatic glaucoma, glaucoma associated with aphakia severe congenital/developmental glaucoma, postretinal surgery glaucoma, glaucoma associated with penetrating keratoplasties, and glaucoma in eyes with scarred conjunctiva from surgery or disease processes. ${ }^{22}$ Delgado et al. (2003) reported that use of noncontact transscleral neodymium:yttrium-aluminum-garnet cyclophotocoagulation for NVG in 115 eyes, while providing long-term IOP reduction, was associated with complications that included inflammation, visual loss, and hypotony, and that repeat treatments may be necessary to main good control of IOP. ${ }^{27}$ Table 1showed demographics and treatment results of Transscleral diode laser cyclophotocoagulation at the different studies.

\begin{tabular}{lccccc}
\hline & $\begin{array}{c}\text { No. of } \\
\text { eyes (\%) }\end{array}$ & $\begin{array}{c}\text { Age (yrs) } \\
\text { (range) }\end{array}$ & $\begin{array}{c}\text { Follow- } \\
\text { up (mos) }\end{array}$ & $\begin{array}{c}\text { Successfully } \\
\text { treated eyes } \\
(\%)\end{array}$ & $\begin{array}{c}\text { Reference } \\
\text { number }\end{array}$ \\
A. Mistlberger et al & 93 & $9-92$ & 12 & $74.2 \%$ & 19 \\
Mr J P Diamond et al & 263 & $4-99$ & 17 & $89 \%$ & 15 \\
Ness et al & 32 & $22-92$ & 17.1 & 28.6 & 17 \\
Bloom et al & 34 & & 34.1 & 34.1 & 9 \\
Sood and Beck & 9 & $1-15$ & 12 & $66.7 \%$ & 13 \\
Jimmy et al & 14 & $48-76$ & 12 & $92.3 \%$ & 16 \\
\hline T. Schlote et al. & 93 & $9-92$ & 12 & $74.2 \%$ & 21 \\
\hline $\begin{array}{l}\text { F. A. Hauber and W. J. } \\
\text { Scherer }\end{array}$ & 47 & $38-100$ & 12 & $94.4 \%)$ & 24 \\
\hline Ataullah, Biswas, Artes, & 53 & $6-90$ & 23.1 & $84 \%$ & 25 \\
et al & 131 & $69-84$ & 30.1 & $69.5 \%$ & 26 \\
\hline Iliev, Gerber
\end{tabular}

Table 1. Demographics and treatment results of Transscleral diode laser cyclophotocoagulation at the different studies 
Previous studies have demonstrated this, with ocular hypotensive responses.7-9 Our study showed that in $50.6 \%$ of patients the IOP was below $21 \mathrm{mmHg}$.

Complications of transscleral Diode CPC include conjunctival surface burns that may occur if tissue debris becomes coagulated on the tip and chars. We inspected all tips for this and found no debris. In addition, increased perilimbal conjunctival pigmentation may occur. One of patients had hypotony and phthisis after treatment 21 months after treatment. The risks of hypotony and phthisis are directly proportional to the dosage of laser energy delivered in a treatment session, ${ }^{7}$ although, a clear relationship between treatment energy and IOP response, which is essential to accurate prediction of desirable effect, remains to be demonstrated. The published literature suggests that this type of treatment is usually reserved for eyes with end stage disease and poor visual potential. In conclusion, this study showed an increase of visual acuity after transscleral Diode laser cyclophotocoagulation therapy. Diode laser cyclophotocoagulation produces very characteristic injury to pars plicata, which frequently extends into pars plana, but with only mild persisting inflammation. Ciliary processes are, however, frequently spared within the treatment zone and may account for early or late treatment failure.22-24

Histopathological studies of enucleation specimens following laser cyclophotocoagulation (Diode and Nd:YAG laser) and cyclocryotherapy have been performed in humans ${ }^{25-29}$ and animals. ${ }^{12}$, 30-35 We have previously reported histopathology of two cases of clinical failure following Diode laser cyclophotocoagulation. ${ }^{36}$ This study examines histological outcomes in nine cases in humans, and correlates this with the clinical c course in each eye. ${ }^{28}$ Repeated use of the G-probe in transscleral cyclophotocoagulation, with ethylene oxide sterilization in between, resulted in an average decrease of $3 \%$ in laser energy delivered per repeated cycle of use up to the fourth cycle. No signs of physical damage were found.25-28

Laser G-probes remain functional after repeated use and ethylene oxide resterilization for up to four cycles. No visible physical damage to the probes was identified. It is safe and cost-effective to reuse G-probe for transscleral cyclophotocoagulation with ethylene oxide sterilization, provided the surgeon stays alert for signs of probe damage. This alertness should be retained regardless of whether new or old G-probes are used.29-30 We noticed microscopic contamination of the G-probe by the tear film fluid in all the probes examined by us. The review of literature indicates that repeated use of the G-probe is not uncommon. The types of techniques used for making it suitable for repeated use indicate that it is not universally recognized that the lumen of the G-probe can accumulate fluid during the procedure, which makes it potentially hazardous when used for other patients.

Treatment with cyclophotocoagulation in patients with refractory glaucoma leads to increase in acuity and lower intraocular pressure. In our opinion the G-probe should not be reused as inadequately reprocessed G-probe can lead to risk of nosocomial infections, serious iatrogenic complications, and medico-legal problems. ${ }^{30}$ Underlying diagnosis of neovascular glaucoma is a significant risk factor for hypotony post TCP. Hypotony was defined as IOP $<5$ at the end of 1 -year follow-up period. Factors, such as underlying diagnosis, total energy used, age, earlier operations, and retreatment rates, which may influence the development of hypotony were analyzed using univariate analysis. ${ }^{31}-32$

CycloDiode therapy is highly effective but there is a significant risk of hypotony, which may be reduced by applying lower energy in cases of very high pretreatment IOP and in neovascular glaucoma.The dose-response association remains unpredictable, although a linear relation was found for neovascular glaucoma. Cyclophotocoagulation is necessary in some intractable cases but should be avoided whenever possible because of its potential 
adverse effects on the lens and the retina. retrobulbar alcohol injection, retrobulbar chlorpromazine injection, or enucleation are rarely performed now because of improved $\mathrm{CPC}$ techniques.

\section{References}

[1] The Eye M,D, Association. Glaucoma In: Basic and Clinical Science Course; The American Academy of Ophthalmology: Copyright @2008. San Francisco LEO 2009; pp: 214-15.

[2] Kanski J. Glaucoma In Clinical Ophthalmology. $6^{\text {th }}$ ed. Butherworth Heinmann Elsevier London, 2007. 429-431

[2] Youn J, Cox T, Herndon L, Allingham R, Shields M. (1998). A Clinical Comparison of Transscleral Cyclophotocoagulation with Neodymium: YAG and Semiconductor Diode Lasers. Am J Ophthalmol, Vol. 126, pp. 640-47.

[3] Kirwan J, Shah P, Khaw P. (2002) Diode Laser Cyclophotocoagulation: Role in the Management of Refractory Pediatric Glaucomas. Ophthalmology, Vol. 109, pp. 316-23.

[4] Semchyshyn T, Tsai J, Joos K. (2002) Supplemental Transscleral Diode Laser Cyclophotocoagulation after Aqueous Shunt Placement in Refractory Glaucoma Ophthalmology, Vol. 109, pp. 1078-84.

[5] Lai J, Tham C, Chan J, Lam D. (2005) Diode laser transscleral cyclophotocoagulation as primary surgical treatment for medically uncontrolled chronic angle closure glaucoma: long-term clinical outcomes. Glaucoma, Vol. 14, pp. 114-19.

[6] Waggle N, Freedman S, Buckley E, Davis J, Biglan A. (1998) Long-term outcome of Cyclocryotherapy for Refractory Pediatric Glaucoma. Ophthalmology, Vol. 105, pp. 1921- 27

[7] Vernon S, Koppens J, Menon J, Negi A. (2006) Diode laser cycloablation in adult a results of standard protocol and review of current literature. Clinical and Experimental Ophthalmology, Vol. 34, pp. 411-20.

[8] Agarwal H, Gupta V, Sihota R. (2004) Evaluation of contact versus non-contact Diode laser cyclophotocoagulation for refractory glaucomas using similar energy Clin Exp Ophthalmol, Vol. 32, pp. 33-38

[9] Bloom P, Tsai J, Sham K. Miller M. Rice N, Hitchings R. (1997) “Cycloid“Trans-scleral Diode laser cyclophotocoagulation in the treatment of advanced refractory glaucoma. Ophthalmology, Vol. 104, pp. 1519-29.

[10] Wong E, Chew P, Chee C, Wong J. (1997) Diode laser contact transscleral cyclophotocoagulation for refractory glaucoma in Asian patients. Am J Ophthalmol, Vol. 124, pp. 797-04.

[11] Goldenberg-Cohen N, Bahar I, Ostashinski M, Lusky M, Weinberger D, Gaton DD. (2005) Cyclocryotherapy versus transscleral Diode laser cyclophotocoagulation for uncontrolled intraocular pressure. Ophthalmic Surg Lasers Imaging, Vol. 36, pp. 272-9.

[12] Pastor S, Singh K, Lee D, Juzych M, Lin S, Netland P, et al. (2001) Cyclophotocoagulation A Report by the American Academy of Ophthalmology. Ophthalmology, Vol. 108, pp. 2130-36.

[13] Shalini Sood, MDa,b and Allen D. (2009) Cyclophotocoagulation versus sequential tube shunt as a secondary intervention following primary tube shunt failure in pediatric glaucoma, J AAPOS. Vol. 13, pp. 379-383.

[14] Cioffi G, Durcan J, Girkin C, Gross R, Netland P, Samples J, Samuelson T. (2009-2010) Surgical Therapy for Glaucoma, American Academy of Ophthalmology 
[15] Murphy C, Spry P, Burnett C, Broadway C, Diamond D. (2003) Two centre study of the dose-response relation for transscleral Diode laser cyclophotocoagulation in refractory glaucoma. Br J Ophthalmol, Vol. 87, pp. 1252-1257

[16] Jimmy S. M. Lai, FRCS, FRCOphth, ${ }^{*} \dagger$ Clement C. Y. Tham, FRCS*§ Jonathan C. H. Chan, MRCSEd, ${ }^{*} \dagger$ and Dennis S. C. Lam, FRCS, FRCOphth* ${ }^{\star}(\mathrm{J}$ Glaucoma 2005;14:114-119)

[17] Ness P, Khaimi M, Feldman R, Tabet R, Sarkisian S, Skuta G, Chuang A, and Mankiewicz K. Intermediate Term Safety and Efficacy of Transscleral Cyclophotocoagulation After Tube Shunt Failure. J Glaucoma 2011;00:000-000

[18] Hollander D, Lin S. Delayed therapeutic success with endoscopic cyclophotocoagulation in treating refractory post-penetrating keratoplasty glaucoma. $\mathrm{Br} \mathrm{J}$ Ophthalmol 2003;87:791-803

[19] Mistlberger A, Liebmann J, Tschiderer H, Ritch R, Ruckhofer J, and Grabner G.Contact Diode laser transscleral cyclophotocoagulation is useful in eyes with refractory glaucoma in which the risks of outflow surgery are deemed, Journal of Glaucoma 10:288-293

[20] Lai J, Tham C, Chan J, and Lam D. Diode Laser Transscleral Cyclophotocoagulation in the Treatment of Chronic Angle-Closure Glaucoma: A Preliminary Study. Journal of Glaucoma 12:360-364

[21] Schlote T, Derse M, Rassmann K Nicaeus T, Dietz K, and Thiel H. Efficacy and Safety of Contact Transscleral Diode Laser Cyclophotocoagulation for Advanced Glaucoma.Journal of Glaucoma 10:294-301

[22] Lin S. Endoscopic and Transscleral Cyclophotocoagulation for the Treatment of Refractory Glaucoma. J Glaucoma 2008;17: 238-247

[23] S Lin.Endoscopic cyclophotocoagulation.Br J Ophthalmol 2002;86:1434-1438

[24] Hauber A, Scherer W. Influence of Total Energy Delivery on Success Rate after Contact Diode Laser Transscleral Cyclophotocoagulation: A Retrospective Case Review and Meta-analysis.Journal of Glaucoma 11:329-333

[25] S Ataullah, S Biswas, P H Artes, E O’Donoghue, A E A Ridgway, A F Spencer. Long term results of Diode laser cycloablation in complex glaucoma using the Zeiss Visulas II system Br J Ophthalmol 2002;86:39-42

[26] M E Iliev, S Gerber. Long-term outcome of trans-scleral Diode laser cyclophotocoagulation in refractory glaucoma. Br J Ophthalmol 2007;91:1631-1635.

[27] Hayreh S. Neovascular glaucoma.Prog Retin Eye Res. 2007 September; 26(5): 470-485 NVG is a severely blinding,

[28] McKelvie P, Walland M. Pathology of cycloDiode laser: a series of nine enucleated eyes. Br J Ophthalmol 2002;86:381-386

[29] Tham C, Lai J, Fung P, Chua J, Poon A, and Lam D. Physical Effects of Reuse and Repeated Ethylene Oxide Sterilization on Transscleral clophotocoagulation Laser G-Probes Journal of Glaucoma 11:21-25

[30] Bansal A, and Ramanathan.Potential Contamination of the G-probe Used for Transscleral CycloDiode(J Glaucoma 2008;17:157-158)

[31] Hla Myint Htoon, PhD,z Ching Lin Ho, MMed (Ophth), MMed(Paed), FRCS (Ed), ${ }^{*}$ Tin Aung, MMed (Ophth), FRCS(Ed), PhD, ${ }^{*}$ zy and Shamira Perera, MBBS, BSc, FRCOphth Ramli N,.Risk Factors for Hypotony After Transscleral Diode Cyclophotocoagulation., (J Glaucoma 2010;00:000-000)

[32] Alipanahi R. (2008) Long-Term Outcome of Transscleral Diode Laser Cyclophotocoagulation for Refractory Glaucoma. Rawal Med J, Vol. 33, pp. 173-175. 


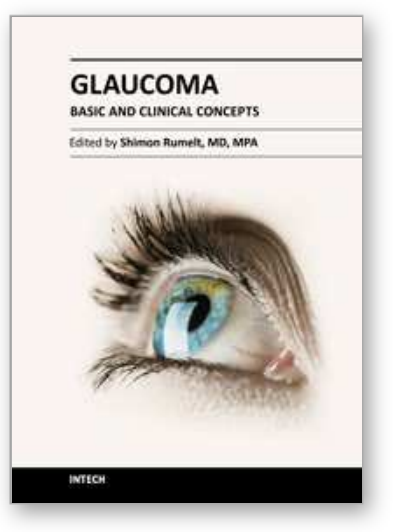

\author{
Glaucoma - Basic and Clinical Concepts \\ Edited by Dr Shimon Rumelt
}

ISBN 978-953-307-591-4

Hard cover, 590 pages

Publisher InTech

Published online 11, November, 2011

Published in print edition November, 2011

This book addresses the basic and clinical science of glaucomas, a group of diseases that affect the optic nerve and visual fields and is usually accompanied by increased intraocular pressure. The book incorporates the latest development as well as future perspectives in glaucoma, since it has expedited publication. It is aimed for specialists in glaucoma, researchers, general ophthalmologists and trainees to increase knowledge and encourage further progress in understanding and managing these complicated diseases.

\title{
How to reference
}

In order to correctly reference this scholarly work, feel free to copy and paste the following:

Sima Sayyahmelli and Rakhshandeh Alipanahi (2011). Cyclodestructive Procedures, Glaucoma - Basic and Clinical Concepts, Dr Shimon Rumelt (Ed.), ISBN: 978-953-307-591-4, InTech, Available from: http://www.intechopen.com/books/glaucoma-basic-and-clinical-concepts/cyclodestructive-procedures

\section{INTECH}

open science | open minds

\author{
InTech Europe \\ University Campus STeP Ri \\ Slavka Krautzeka 83/A \\ 51000 Rijeka, Croatia \\ Phone: +385 (51) 770447 \\ Fax: +385 (51) 686166 \\ www.intechopen.com
}

\author{
InTech China \\ Unit 405, Office Block, Hotel Equatorial Shanghai \\ No.65, Yan An Road (West), Shanghai, 200040, China \\ 中国上海市延安西路65号上海国际贵都大饭店办公楼 405 单元 \\ Phone: +86-21-62489820 \\ Fax: +86-21-62489821
}


(C) 2011 The Author(s). Licensee IntechOpen. This is an open access article distributed under the terms of the Creative Commons Attribution 3.0 License, which permits unrestricted use, distribution, and reproduction in any medium, provided the original work is properly cited. 